\title{
Intelligent control of DC-DC converter based on PID-neural network
}

Hussain K. Khleaf, Ali K. Nahar, Ansam S. Jabbar

Department of Electrical Engineering, University of Technology, Iraq

\begin{tabular}{|c|c|}
\hline Article Info & ABSTRACT \\
\hline Article history: & \multirow{9}{*}{$\begin{array}{l}\text { This paper introduced a "PID-NN" based on Particle Swarm Optimization } \\
\text { control that was applied to a boost converter operating in large-signal } \\
\text { domains. Simulation results have shown that the proposed "PID-NN } \\
\text { controller" could enhance the (boost converter) startup response with the use } \\
\text { of fewer on-off switch operations compared to the Conventional "PID } \\
\text { controllers". This result has been of high importance in practice for reducing } \\
\text { the number of on-off switches can effectively decrease the transient } \\
\text { disturbances and losses due to switching. Simulations also prove that the } \\
\text { proposed "PID-NN controller" is capable of efficiently, improving rejecting } \\
\text { potential disturbances that could happen in the input voltage. Moreover, it } \\
\text { has been noticed that the output voltage is more efficiently controlled when } \\
\text { applying "PID-NN controller". The results of the simulation show the } \\
\text { efficiency of the suggested algorithm compared with other well-known } \\
\text { learning methods. }\end{array}$} \\
\hline Received Apr 18, 2019 & \\
\hline Revised Jul 14, 2019 & \\
\hline Accepted Jul 29, 2019 & \\
\hline Keywords: & \\
\hline DC-DC boost converter & \\
\hline PID based on a neural network & \\
\hline Conventional PID controller & \\
\hline Particle swarm optimization & \\
\hline
\end{tabular}

Copyright (C) 2019 Institute of Advanced Engineering and Science. All rights reserved.

\section{Corresponding Author:}

Hussain K. Khleaf, Department of Electrical Engineering, University of Technology, Baghdad, Iraq. Email: 30068@uotechnology.edu.iq

\section{INTRODUCTION}

By way of the industrial development, control objects keep getting more complicated, particularly for the unknown parameters or slow variations in large delay, time-changing, non-linear complicated systems, with random interference or delay. However, The Proportional Integral Derivative (PID) control has simple structure and linear behaviour. Moreover, it gives acceptable performance for several industrial applications [1]. The "PID controller" is one of the traditional controllers which are usually used in many drive systems. However, it is sluggish response due to sudden change in power and the sensitivity to controller gains [2] the conventional "PID control" parameters will not change post completion, which will result in parameter changes of controlled objects that can't be traced in real time, cannot satisfy growing needs of control quality in the process of production, this is why, scholars improved a range of enhancements for Conventional "PID controller", especially in 2 aspects: one of them is improving structure, which is, variable structure control [3]. Recently, the use of intelligent control like Neural Network, Neuro Fuzzy and fuzzy control, the fuzzy logic control can answer the uncertainty problem and sudden disturbance, on the other hand its design depends on the experience which sometimes is not available for some systems [1]. In addition, it can add control non-linear systems, which would be hard or not possible to model mathematically. An artificial neural network could be applied to a wide range of tasks like signal processing, pattern recognition, function approximation, and classification. Usually, there are two operations when utilizing neural networks for control, those operations are [4], System identification and Control design [4]. The PSO algorithm can lead to a higher quality solution with time and secure convergence in comparison with other stochastic methods [5]. In addition, Meta Heuristic methods have had a profound effect on optimization in modified engineering streams. The efficiency of these algorithms is important as the 
hardware application of these algorithms for various engineering applications is to be carried out [6]. PSO, as one of the meta-heuristic methods of optimization, relies on the thorough search area's ideal solution based on the exchange of experiences among the population's particles. [7]. Moreover, PSO is a swarm-based metaheuristic algorithm with some intrinsic inconveniences that weak local search and slow convergence rate and trapping in local optimum when solving complicated multi-modal issues [8]. Also, one of the most problem a range of DC-voltage of these sources have low output levels, unstable, the settling time is too tall moreover. There are also many situations where loss may be either unnoticeable or acceptable [9] compare with other techniques like (PID-NN), therefore the suggested new configurations of the intelligent (PID-NN) and optimized by using PSO method applied to the "Boost converter" due to several reasons and will be implemented to better optimize boost converter stability compared to the conventional "PID". High voltage increases and decreased steady-state error are the advantages of the proposed scheme [10].

\section{BOOST CONVERTER}

Recent electronic systems involve highly efficient resources. By replacing diode with MOSFET [11], the effectiveness of (DC to DC converters) such as the energy source of electronic equipment can be improved. (DC / DC converter) can be used for different applications such as voltage output control, electric vehicle energy storage system, renewable power storage system, [12] a "DC-DC boost" Converter switching was intended to show the scheme proposed. The boost energy phase output current is either constant or nonpulsing. [13] Considering the "DC-DC boost" as converter circuit which is depicted in Figure 1. Through the interval, when the $\mathrm{Q}$ switch is off, (diode) D conducts the current $\mathrm{i}_{\mathrm{L}}$ of inductor $\mathrm{L}$ on the way to the capacitor $\mathrm{C}$ and the load $\mathrm{R}_{\mathrm{O}}$. For the duration of the interval, when the $\mathrm{Q}$ switch is on the diode $\mathrm{D}$ opens and the $\mathrm{C}$ discharges through the $\mathrm{R}_{\mathrm{c}}$ as shown in Figure 1 . The converter transmits the energy between the input and the output with the use of the inductor. A "DC-DC Boost" converter design instance is available to achieve the efficiency needed for the implementation listed below. The simulation package MATLAB / Simulink was used to check the theoretical projections [13].

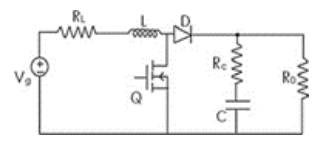

Figure 1. Boost converter.

In Figure 1, transfer function that is derived with useing of the approach of standard state space averaging, where the circuits for the two a operational mode ON and OFF mode for the converter are modelled in the following way:

$$
\begin{aligned}
& \dot{x}=A_{x}+B_{u} \\
& y=C_{x}+D_{u}
\end{aligned}
$$

where: $u, y$ input, output voltage (Vin, Vo) and $x$ state variable.

The post is modelled, the average of those two modes over one switching period $\mathrm{T}$ is calculated [14].

\section{THE PROPORTIONAL INTEGRAL DERIVATIVE (PID) CONTROL PRINCIPLE}

"Controller PID" is one of the traditional controllers of many drive systems. [2]. The Conventional "controller PID" which is depicted in Figure 2 includes 3 distinct action parameters, which are the Integral, Derivative and Proportional. Those 3 parameters from the computation of "PID" [15]. Conventional "PID controller" in the process of production is the most often utilized control approach, commonly implemented in chemical, machinery, metallurgy and extra industries [16]. In other side, the simulated of control system is Conventional "PID controller" based on the deviation differential (D), proportion (P) and integral (I) are the most commonly implemented controller automatic [3].

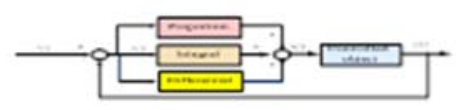

Figure 2. Conventional controller PID principle. 
The proportional value regulates the reaction to the instantaneous error; the integral value regulates the reaction according to the summation of recent errors and the derivative value regulates the reaction according to the rate of the error changes. By through them, $y(t)$ is the effective output value while, $r(t)$ is the given value. Then, $\mathrm{e}(\mathrm{t})=\mathrm{r}(\mathrm{t})-\mathrm{y}(\mathrm{t})$, Conventional "PID controller" when the equation is:

$$
u(t)=\left(e(t)+\frac{1}{T_{i}} \int_{0}^{t} e(t) d t+T_{d} \frac{d}{d t} e(t)\right) k_{p}
$$

where, $T_{i}$ and $T_{d}$ are the integral and derivative time constants respectively [15].

\subsection{Discrete representation of the Conventional PID controller}

In the past years, analog controllers were typically replaced with digital controllers that the outputs and inputs are characterized at discrete time instances. Moreover, the digital controllers as possible to be in the form of digital computer, digital circuits or microprocessors. The discrete-time Conventional "PID controller" means discretizing the continuous-time to discrete-time. The discrete Conventional can be represented as follows:

Consider the continuous time expression of a Conventional "PID controller" in (2), If the sapling time of discretization is $\Delta t$. Then the integral term above can be measured "discrete" via a trapezoidal approximation:

$$
\int_{0}^{t} e(t) d t \cong \sum_{i=1}^{k} e\left(t_{i}\right) \Delta t
$$

where, $e\left(t_{i}\right)$ the error of the discrete time system at the $i$-th sampling instant. Similarly, the backward-finite difference approximation of the first-order derivative:

$$
f^{\prime}(t) d t=\lim _{\Delta t \rightarrow 0}\left[\frac{f(t)-f(t-\Delta t)}{\Delta t}\right]
$$
becomes:

Appling the backward-finite difference approximation to the discrete time derivative term in (2)

$$
\frac{d}{d t} e\left(t_{i}\right) \cong \frac{e\left(t_{i}\right)-e\left(t_{i-1}\right)}{\Delta t}
$$

Therefore, the discrete time control law, or "positional algorithm", comes to be,

$$
u\left(t_{k}\right)=k_{p}\left(e(k)+\frac{\Delta_{t}}{T_{i}} \int_{i=1}^{k} e\left(t_{i}\right)+T_{d} \frac{e\left(t_{i}\right)-e\left(t_{i-1}\right)}{\Delta t}\right)
$$
from $u(t k)$.

An "incremental algorithm" or "velocity algorithm" may be obtained by subtracting $(t k-1)$

$$
\begin{gathered}
u\left(t_{k-1}\right)=k_{p}\left(e(k-1)+\frac{\Delta t}{T_{i}} \sum_{i=1}^{k} e\left(t_{i-1}\right)+T_{d} \frac{e\left(t_{i-1}\right)-e\left(t_{i-2}\right)}{\Delta t}\right. \\
\Delta u\left(t_{k}\right)=u\left(t_{k}\right)-u\left(t_{k-1}\right) \\
u\left(t_{k}\right)=k_{p}\left(e(k)-e(k-1)+\frac{\Delta t}{T_{i}} \sum_{i=1}^{k} e\left(t_{i}\right)-e\left(t_{i-1}\right)+T_{d} \frac{e\left(t_{i}\right)-e\left(t_{i-1}\right)}{\Delta t}-\frac{e\left(t_{i-1}\right)-e\left(t_{i-2}\right)}{\Delta t}\right)
\end{gathered}
$$

This can be rewritten as:

$$
u\left(t_{k}\right)=u\left(t_{k-1}\right)+k_{p}\left(e\left(t_{k}\right)-e\left(t_{k-1}\right)\right)+k_{i} e\left(t_{k}\right)+k_{d}\left(e\left(t_{k}\right)-2 e\left(t_{k-1}\right)+e\left(t_{k-2}\right)\right)
$$

where, $k_{i}=\frac{\Delta t k_{p}}{T_{i}}, k_{d}=\frac{T_{d} k_{p}}{\Delta t}$

\subsection{Neural Network controller of PID}

The drawback of the Conventional "controller PID" is not appropriate for long time delay and nonlinear system control [17]. Where D, P and I parameters tuning is difficult with the way modern computer technology has developed, in addition to the control theories like fuzzy and neural networks. The adaptive Conventional "controller PID" based on Back Propagation (BP) and neural network are designed to combine the traditional strategy of the Conventional "PID controller" with using the neural network has produced a novel idea, also design the new control scheme. However, the ability of self-learning of neural network and 
Back Propagation can automatically tune and update the parameters of robust Conventional "PID controller", because it is combined between them could give good results. Figure 3 shown of the "PID controller" block diagram based on neural network [18].

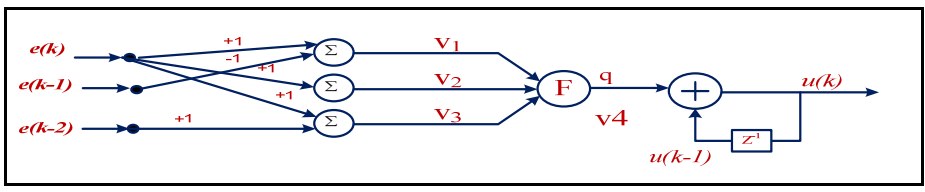

Figure 3. The neural network based on controller of PID.

The presented adaptive control law using neural network technique is for example the next equation:

$$
n e t(k)=V_{1}[e(k)-e(k-1)]+V_{2} e(k)+V_{3}[e(k)-2 e(k-1)+e(k-2)]
$$

where; $e(k), e(k-1)$ and $e(k-2)$ are the input vectors. $\mathrm{q}$ is the neural networks that can be obtained from the activation function "F":

$$
q=\frac{2}{1+e^{-2 n e t} 1,2}-1
$$

The control law of the controller action:

$$
u(k)=u(k-1)+q v_{4}
$$

The control parameters of the "PID-NN controller" are $V_{1}-V_{4}$ [18].

In spite of the BP is a universal computing technique which is widely used to determine the neural network weights. Also has their shortage that has long training time. To improve the convergent speed, the Particle Swarm Optimization (PSO) algorithm can be adopted to evaluate the "PID" neural network parameters.

\subsection{PID-NN Based on "PSO"}

The PSO technique is firstly presented by Eberhart and Kennedy in the year of 1995 [19]. This technique used a multi-variable functional with multi-local optimum points. The fundamental of this algorithm utilize the behaviour of the bird's flock. In conjunction with other optimization methods the PSO has features of fast convergence and easy implementation. This method depends on monitoring the movement of flocks where 'birds', called particles, cooperate with each other and interact together in the 'flock' which is called a swarm. The moving steps of each bird characterized by its velocity and an objective which formed the fitness of the swarm motion [15]. The moving step of the particle depends on the optimal position of the individual particle $\left(p_{\text {best }}\right)$ and optimal position in the neighbourhood particle $\left(g_{\text {best }}\right)$, which are saved in the best global position of the flock. This global best position used to move particles in the direction of the best position, and updating its velocity and direction as required. This approach leads to guide all particles in the swarm to the optimum (best) value (position) [20]. The following equation defines the standard form of the PSO algorithm:

$$
\begin{aligned}
& v_{i}(k+1)=W v_{i}(k)+C_{1} R_{1}\left(p_{\text {best }}-x_{i}(k)\right)+C_{2} R_{2}\left(g_{\text {best }}-x_{i}(k)\right) \\
& x_{i}(k+1)=x_{i}(k)+v_{i}(k+1) \\
& i=1,2, \ldots n
\end{aligned}
$$

$x_{i}$ and $v_{i}$ are position and velocity of particle $i, k$ denotes the number of the iteration, while, $\mathrm{R}_{1}$ and $\mathrm{R}_{2}$ are random variables that have their values evenly distributed in the range between $(0,1), W$ is the inertia weight and $\mathrm{C}_{1}$ and $\mathrm{C}_{2}$ represent the cognitive coefficient and the social coefficient. $p_{\text {best }, i}$ is the individual optimal position of particle $i$, and $g_{b e s t, i}$ is the optimal global position of all of the swarm particles. $n$ is the number of birds (i.e. particles). If the condition (16) is satisfied, the position of the particle is corrected according to (17):

$$
\begin{aligned}
& f\left(x_{i k}\right)<f\left(p_{\text {best }, i}\right) \\
& p_{\text {best }, i}=x_{i k}
\end{aligned}
$$


where; $f$ is the fitness function that should be minimized.

In addition, the PSO algorithm is used to evaluate optimum values of the "PID-NN controller" weights instead of applied the traditional BP method as shown in Figure 4.

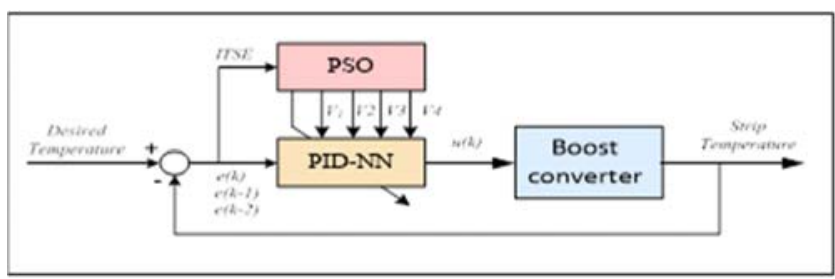

Figure 4. The building of the optimized "PID-NN controller".

A MATLAB program is developed to find the optimal values of the controller parameters $V_{1}-V_{4}$. The integral time square error (ITSE) is used, for example, an objective fitness function of the system performance, a minimization algorithm is applied in the search domain of the particles position and velocity.

$$
I T S E=\int t e^{2} d t
$$

\section{SIMULINK MODEL AND RESULTS}

For the sake of verifying the performance of the proposed design we have developed a model of the converter in (MATLAB-Simulink), and the most important results will be presented here. Figure 5 present the model for this controller for "Boost converter".

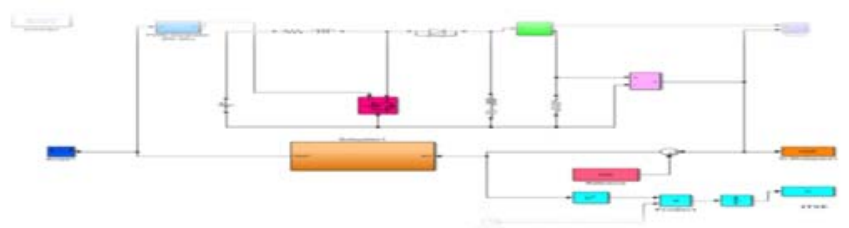

Figure 5. Boost converter model.

To design the suitable controller and adjusting the controller parameters, it's required to employ suitable model. The proposed intelligent model can be used efficiently in this work to design and optimize the controller parameters. The performance of the optimization algorithm, by using the optimizing coefficients $\mathrm{C} 1=\mathrm{C} 2=1.3$ and $\mathrm{W}=0.9$, gives the optimum values of the "PID-NN controller" in 10 iterations as the following: $\mathrm{V} 1=1.6901 \mathrm{e}-05, \mathrm{~V} 2=2.9139 \mathrm{e}-06, \mathrm{~V} 3=9.2440 \mathrm{e}-06, \mathrm{~V} 4=1.21579 \mathrm{e}-05$. The control signal system input is the ranged from 0 to $40 \mathrm{~V}$ and limited within this range. The optimization performances are shown in Figures 6, 7,8 and 9:

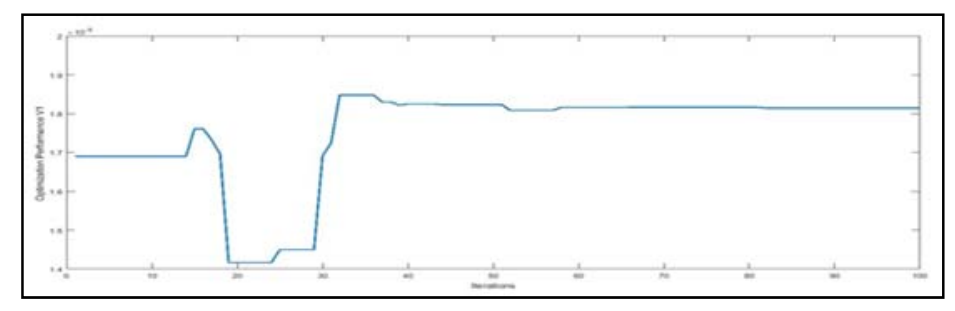

Figure 6. The optimization performance at V1.

Int J Pow Elec \& Dri Syst Vol. 10, No. 4, Dec 2019 : $2254-2262$ 


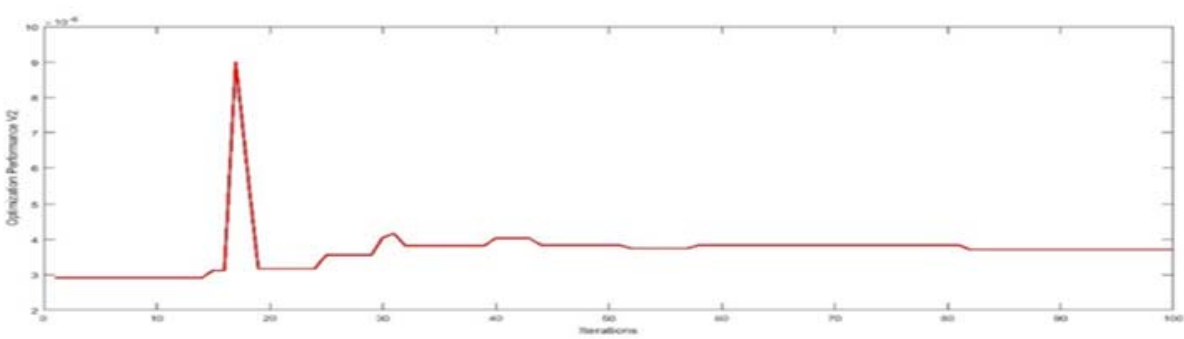

Figure 7. The optimization performance at V2.

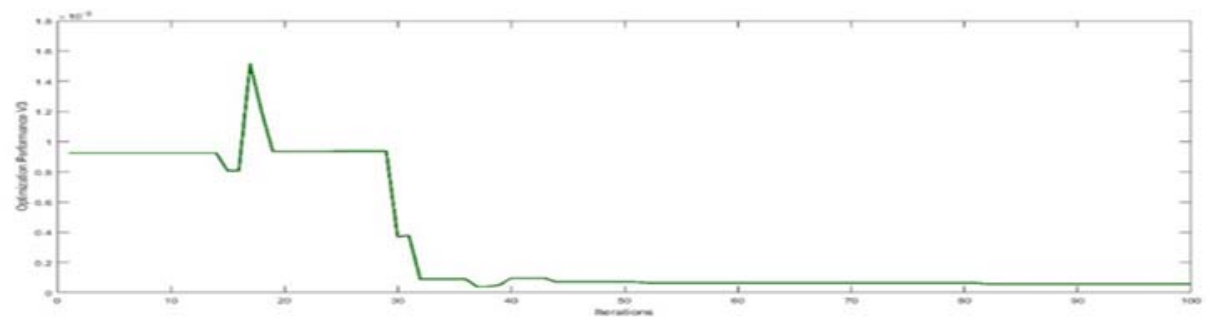

Figure 8. The optimization performance at V3.

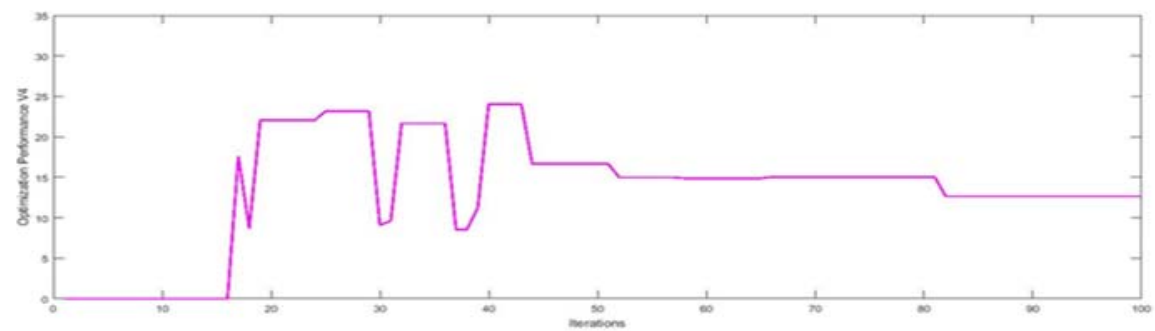

Figure 9. The optimization performance at V4.

From the response it is clear that after $10 \mathrm{~ms}$ output voltage is restored to its original value. This segment includes a comparison between the output results obtained by applying Conventional "PID controller" and "PID-NN" Based on Particle Swarm Optimization controllers to the boost converter so the suggested control strategy could brand the "boost converter" functioned in a stable manner under big load transient responses of all the quiescent input DC-voltage range as shown in Figures 10, 11, 12 and 13.

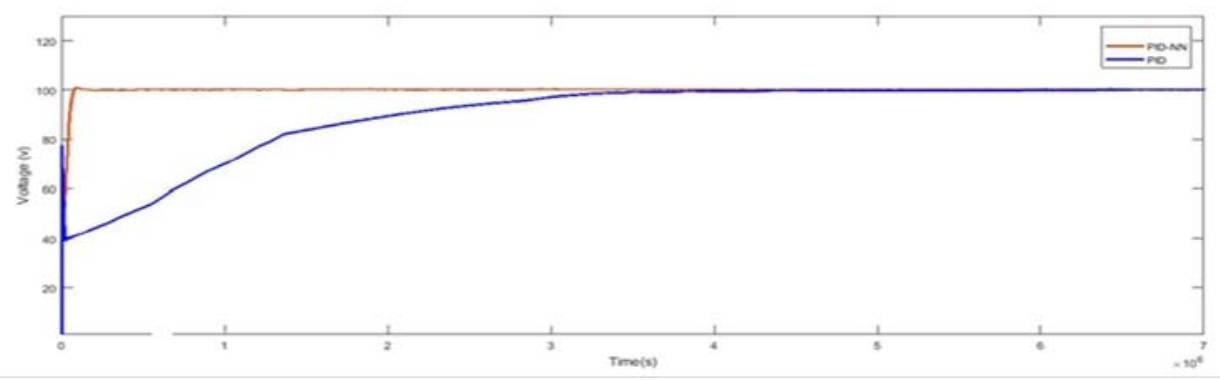

Figure 10. Comparison output voltage of the boost converter with conventional PID and PID-NN controller for $100 \mathrm{v}-100 \Omega$. 


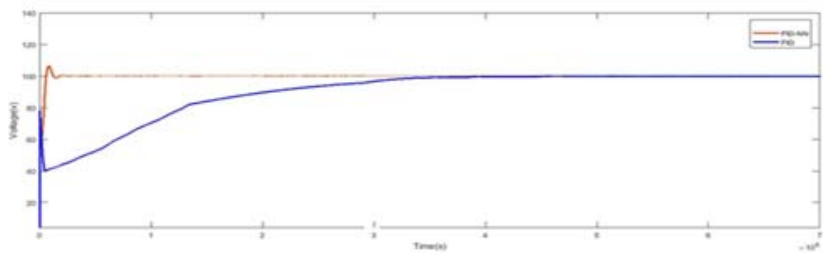

Figure 11. Comparison Vo of the boost converter through conventional PID and PID-NN controllers for $100 \mathrm{v}-200 \Omega$.

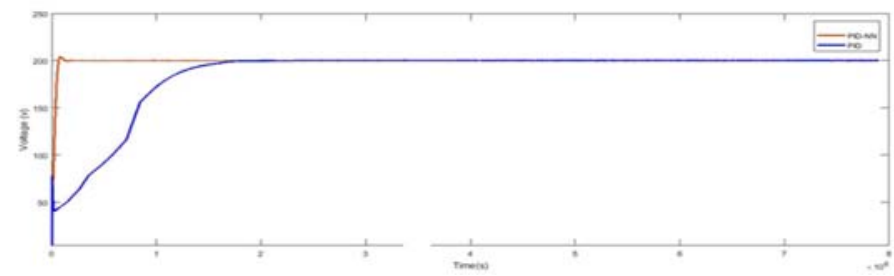

Figure 12. Comparison output voltage of the boost converter with conventional PID and PID-NN controllers for $200 v-100 \Omega$.

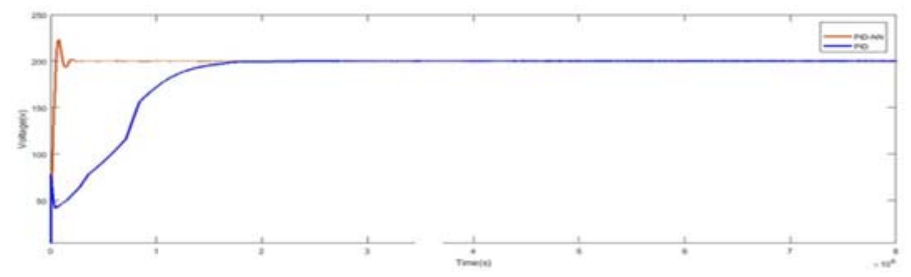

Figure 13. Comparison output voltage of the boost converter with conventional PID and PID-NN controllers for $200 \mathrm{v}-200 \Omega$.

\section{COMPARISON ANALYSIS AND DISCUSSIONS}

The problems can be identified from the previous figures in the Conventional PID controller:

- The settling time is too long.

- During the transient, the converter operates intermittently in discontinuous conduction mode.

In order to make a better comparison between the performance of the Conventional PID and PID-NN controllers, based on PSO controllers, corresponding steady-state, settling time, overshoot, transient responses and the output voltage are more stable and better regulated when the controller PID-NN is applied as shown in Tables 1-4. In addition, the optimal PID-NN controller leads to a feedback system with a considerable faster response, which allows us to ensure continuous conduction operation of the converter at all times, no overshoots and shorter settling times.

Table 1. Performance analysis of PID-NN with the boost converter at different load and V=100.

\begin{tabular}{ccc}
\hline $\mathrm{V}=100$ & $\mathrm{R}=100$ & $\mathrm{R}=200$ \\
\hline$T_{p}$ & $0.120^{*} 10^{\wedge}-6$ & $0.062^{*} 10^{\wedge}-6$ \\
Settling time $(\mathrm{Sec}) T_{S}$ & $0.093^{*} 10^{\wedge}-6$ & $0.125^{*} 10^{\wedge}-6$ \\
Overshoot (\%) & 2.5 & 7 \\
\hline
\end{tabular}

Table 2. Show analysis of PID-NN with the boost converter at different load and $\mathrm{V}=200$.

\begin{tabular}{ccc}
\hline $\mathrm{V}=200$ & $\mathrm{R}=100$ & $\mathrm{R}=200$ \\
\hline$T_{p}$ & $0.118^{*} 10^{\wedge}-6$ & $0.110^{*} 10^{\wedge}-6$ \\
Settling time $(\mathrm{Sec}) T_{s}$ & $0.06^{*} 10^{\wedge}-6$ & $0.125^{*} 10^{\wedge}-6$ \\
Overshoot (\%) & 3 & 12.5 \\
\hline
\end{tabular}

Int J Pow Elec \& Dri Syst Vol. 10, No. 4, Dec 2019 : $2254-2262$ 
Table 3. Performance analysis of conventional PID controller with the boost converter at different load

\begin{tabular}{ccc} 
& and $\mathrm{V}=100$. \\
\hline $\mathrm{V}=100$ & $\mathrm{R}=100$ & $\mathrm{R}=200$ \\
\hline$T_{p}$ & 100 & 100 \\
Settling time $(\mathrm{Sec}) T_{s}$ & $2.7^{*} 10^{\wedge}-6$ & $2.2^{*} 10^{\wedge}-6$ \\
Overshoot $(\%)$ & 0 & 0 \\
\hline
\end{tabular}

Table 4. Performance analysis of conventional PID controller with the boost converter at different load

\begin{tabular}{ccc} 
& and $\mathrm{V}=200$ \\
\hline $\mathrm{V}=200$ & $\mathrm{R}=100$ & $\mathrm{R}=200$ \\
\hline$T_{p}$ & 200 & 200 \\
Settling time $(\mathrm{Sec}) T_{s}$ & $1.3^{*} 10^{\wedge}-6$ & $1.1^{*} 10^{\wedge}-6$ \\
Overshoot $(\%)$ & 0 & 0 \\
\hline
\end{tabular}

In addition, Table 5 is shown comparison considered the fourth previous works, PID -DOO, Hybrid Adaptive Neuro Fuzzy based speed Controller, Adaptive Neuro-Fuzzy Control Approach for a Single Inverted Pendulum System and GA ANFIS, which have used the same data set. The results show that the "PID-NN with the boost converter" is able to present a higher performance than others in solving all problems.

Table 5. The comparison with previous works

\begin{tabular}{ccccc}
\hline & Reference Article & $T_{p}(\mathrm{Sec})$ & Settling time $(\mathrm{Sec}) T_{s}$ & Overshoot (\%) \\
\hline $\begin{array}{c}\text { PID-NN with the boost converter } \\
\text { PID -DOO (Comparison of the various } \\
\text { buck converter control methods in LED } \\
\text { applications) (Shwetha D.V., et al., 2019) }\end{array}$ & - & $0.062 * 10^{\wedge}-6$ & $0.125^{*} 10^{\wedge}-6$ & 7 \\
$\begin{array}{c}\text { PI (Hybrid adaptive Neuro Fuzzy speed } \\
\text { controller for Brushless DC engine)2017 }\end{array}$ & {$[21]$} & - & $1.07 * 10^{\wedge}-5$ & - \\
$\begin{array}{c}\text { ANFIS (Adaptive Neuro-Fuzzy Pendulum } \\
\text { System Control Approach) 2018 }\end{array}$ & {$[22]$} & 0.025 & 0.075 & 12 \\
$\begin{array}{c}\text { GA ANFIS (Intelligent self-tuning GA } \\
\text { ANFIS Plastic Extrusion System } \\
\text { Temperature Controller design) 2011 }\end{array}$ & {$[24]$} & - & 2.2 & $0.095 \mathrm{rad}$ \\
\hline
\end{tabular}

\section{CONCLUSION}

This article suggests an intelligent PID controller based on ANN and optimized by using PSO method applied to the converter Boost. The intelligent model is used efficiently to adapt and optimize the PID-NN controller, Simulation findings have shown that the PID-NN controller provides a smooth reaction to the reference monitoring and retains the boost converter output voltage according to the required voltage comparative with the Conventional PID controller. This controller can provide a much better reaction to startup than the PID controller for the whole order. The PID-NN controller also has a good dynamic response and an outstanding start-up reaction as shown. Finally, the resulting design was based on the simplicity of this converter, its robustness and its low part count, application in high power high reliability applications. This is especially the case if fast and compact control techniques, like the one presented here, are used that allow for inexpensive and robust controllers use.

\section{REFERENCES}

[1] Mohamed. A. Shamseldin, Mohamed Sallam, A. M. Bassiuny, A. M. Abdel Ghany, "A novel self-tuning fractional order PID control based on optimal model reference adaptive system," International Journal of Power Electronics and Drive System (IJPEDS), vol. 10, no. 1, 2019.

[2] Deepti Yadav, Arunima Verma, "Comperative Performance Analysis of PMSM Drive Using MPSO and ACO Techniques," International Journal of Power Electronics and Drive System (IJPEDS), vol. 9, no. 4, 2018.

[3] Liu Luoren and Luo Jinling," Research of PID Control Algorithm Based on Neural Network, " Journal of Energy Procedia, vol. 13, pp. 6988 - 6993, 2011.

[4] Leila Fallah Araghi, M. Habibnejad Korayem, Amin Nikoobin and Farbod Setoudeh,"Neural Network Controller Based on PID Controller for Two links- Robotic Manipulator Control, " Journal of Engineering and Computer Science WCECS, San Francisco, USA, 2008. 
[5] Mohd Ruddin Ab Ghani, Saif Tahseen Hussein, Zanariah Jano, Tole Sutikno, "Particle Swarm Optimization Performance: Comparison of Dynamic Economic Dispatch with Dantzig-Wolfe Decomposition," TELKOMNIKA (Telecommunication, Computing, Electronics and Control), vol. 14, no. 3, 2016.

[6] T.G. Manjunath, Ashok Kusagur, "Analysis of Different Meta Heuristics Method in Intelligent Fault Detection of Multilevel Inverter with Photovoltaic Power Generation Source," International Journal of Power Electronics and Drive System (IJPEDS), vol. 9, no. 3, 2018.

[7] Yasser Ahmed, Ayman Hoballah, "Adaptive filter-FLC integration for torque ripples minimization in PMSM using PSO," International Journal of Power Electronics and Drive System (IJPEDS), vol. 10, no. 1, 2019.

[8] Zahra Beheshti, Siti Mariyam Hj. Shamsuddin, "A Review of Population-based Meta-Heuristic Algorithm," Int. J. Advance. Soft Comput. Appl., vol. 5, no. 1, 2013.

[9] Ali K. Nahar, Ansam S. Jabbar, Mohmmed J. Mortada,"A Novel Improve and Compression for the Medical Image Technique Based On the Double Density Wavelet," World Wide Journal of Engineering and Technology, 2018.

[10] P. Bhaskara Prasad, M. Padma Lalitha, B. Sarvesh, "Fractional Order PID Controlled Cascaded Re-boost Seven Level Inverter Fed Induction Motor System with Enhanced Response," International Journal of Power Electronics and Drive System (IJPEDS), vol. 9, no. 4, 2018.

[11] Mohamad Isnaeni Romadhon, etc..., "A Comparisson of Synchronous and Nonsynchronous Boost Converter," IAES International Conference on Electrical Engineering, Computer Science and Informatics, 2017.

[12] Chandra Shekher Purohit, etc........,"Performance analysis of DC/DC bidirectional converter with sliding mode and pi controller," International Journal of Power Electronics and Drive System (IJPEDS), vol. 10, no. 1, 2019.

[13] Muhammad Wasif Umar, Norzaihar B Yahaya, Zuhairi B Baharuddin"PWM Dimming Control for High Brightness LED Based Automotive Lighting Applications," International Journal of Electrical and Computer Engineering (IJECE) vol. 7, no. 5, 2017.

[14] P. Siva Subramanian and R. Kayalvizhi. "An Optimum Setting of PID Controller for Boost Converter Using Bacterial Foraging Optimization Technique," Journal of Springer India, 2015.

[15] Prof. Dr. A. K. Al-Shaikhli, Asst. Prof. Dr. Abdul-Rahim T. Humod, Fadhil A. Hasan (MSc), "Traveling Wave Induction Heating Control Based on Robust Intelligent Controller," Advances in Natural and Applied Sciences, vol. 10 , no. 17 , pp. 125-134.

[16] James Carvajar, Guangrong Chen, "Fuzzy PID Controller: Design, performance evaluation and stability analysis," Information Sciences, vol. 123, no. 3, pp. 249-270, 2000.

[17] Beitao Guo, H. Liu, Z. Luo, F. Wang, “Adaptive PID Controller Based on Neural Network," IEEE, International Joint Conference on Artificial Intelligence, 2009.

[18] Ahmed S. Al-Araji, Ahmed I. Abdul Kareem, "A Nonlinear Neural Controller Design for the Single Axis Magnetic Ball Levitation System Based on Slice Genetic Algorithm,"Eng. And Tech. Journal, 34Part(A): 1, 2012.

[19] Ishaque, K. and Z. Salam, "A deterministic particle swarm optimization maximum power point tracker for photovoltaic system under partial shading condition," IEEE Trans. Ind. Electron., vol. 60(8), pp. 3195-3206, 2013.

[20] Lian, K.L., J.H. Jhang and I.S. Tian, "A maximum power point tracking method based on perturb-and observe combined with particle swarm optimization," IEEE J. Photovoltaic, vol. 4(2), pp. 626-633, 2014.

[21] Shwetha D.V., Lakshman Rao S. Paragond,"Comparison of the different controlling techniques for buck converter in LED application," International Journal of Power Electronics and Drive System (IJPEDS), vol. 10, no. 1, 2019.

[22] K. Harshavardhana REDDY, etc...., "Hybrid Adaptive Neuro Fuzzy based speed Controller for Brushless DC Motor," Journal of Science, 2017.

[23] Mohammed A. A. Al-Mekhlafi1, etc....,"Adaptive Neuro-Fuzzy Control Approach for a Single Inverted Pendulum System," International Journal of Electrical and Computer Engineering (IJECE), vol. 8, no. 5, 2018.

[24] S. Ravi, M. Sudha, and P. A. Balakrishnan,"Design of Intelligent Self-Tuning GA ANFIS Temperature Controller for Plastic Extrusion System," Modelling and Simulation in Engineering, 2011.

Int J Pow Elec \& Dri Syst Vol. 10, No. 4, Dec 2019 : 2254 - 2262 